\title{
Reduction of mismatch of global ventilation and perfusion on exercise is related to exercise capacity in chronic heart failure
}

\author{
Neal G Uren, Simon W Davies, John E Agnew, Andrew G Irwin, Sally L Jordan, \\ Andrew J W Hilson, David P Lipkin
}

\begin{abstract}
Background-The inability to match lung perfusion to ventilation because of a reduced cardiac output on exercise contributes to reduced exercise capacity in chronic heart failure.

Objective-To quantify ventilation to perfusion matching at rest and at peak exercise in patients with chronic heart failure and relate this to haemodynamic and ventilatory variables of exercise capacity.

Design-Eight men in New York Heart Association class II underwent maximal bicycle ergometry with expired gas analysis.

Main outcome measures-On separate days, ventilation and perfusion gamma camera imaging was performed at rest, and at $80 \%$ of previous peak exercise heart rate during bicycle ergometry. The vertical distribution of mismatch between ventilation and perfusion (VIQ) was estimated from subtracted profiles of activity (ventilation and perfusion) to derive a numerical index of global mismatch.
\end{abstract}

Results-Maximal mean (SD) oxygen consumption on bicycle ergometry was 16.0 (4.5) $\mathrm{ml} \mathrm{min}^{-1} \mathrm{~kg}^{-1}$. There was a reduction in the global V/Q mismatch index from $23.96(5.90)$ to $14.88(7.90)$ units $(p<0.01)$ at rest and at peak exercise. Global V/Q mismatch index at peak exercise correlated negatively with maximal minute ventilation $(R=-0.90, p<$ $0.01)$ and with maximal mean arterial pressure $(R=-0.79, p<0.05)$, although no relation was seen with maximal oxygen consumption. The reduction in global V/Q mismatch index from rest to peak exercise correlated with maximal oxygen consumption $(R=0.88, p<0.01)$, and with maximal minute ventilation $(R=0.87, p<0.01)$.

Conclusions-During exercise in patients with chronic heart failure, there is a reduction in the global V/Q mismatch index. A lower global VIQ mismatch index at peak exercise is associated with higher maximal ventilation. The reduction in global V/Q mismatch index on exercise correlates well with maximal exercise capacity. This may imply that the inability to perfuse adequately all regions of lung on exercise and match this to ventilation is a factor determining exercise capacity in chronic heart failure.

(Br Heart f 1993;70:241-246)
Introduction

In chronic heart failure, patients ventilate during maximal exercise, more than do normal subjects at the same workload, ${ }^{12}$ leading to an increased ratio of minute ventilation to minute production of carbon dioxide, compared with controls. It is widely believed that this inappropriate increase in ventilation may be partly explained by an increase in physiological dead space secondary to a mismatch between ventilation and perfusion, ${ }^{2-6}$ particularly as there is also a reduced cardiac output in response to exercise in these patients. ${ }^{7}$ As the ventilatory equivalent for carbon dioxide production ratio correlates with maximal oxygen consumption in patients with chronic heart failure but not in normal subjects, it has been postulated that a critical level of cardiac function is necessary to perfuse adequately all lung zones on exercise, thus avoiding significant mismatch between ventilation and perfusion. ${ }^{2}$

In our study, we have used radio isotope scanning to measure regional distribution of lung ventilation and perfusion at rest and during maximal exercise in patients with chronic heart failure. From these data it is possible to calculate a numerical index of mismatch between global ventilation and perfusion to find whether there is a direct relation between the degree of mismatch between ventilation and perfusion and exercise capacity as measured by oxygen consumption.

\section{Patients and methods}

PATIENT POPULATION

Eight men with chronic heart failure, mean (SD) age 66 (7) years were enrolled in the study. Patients were excluded if there was a history of recent angina or ST segment depression $(>0.1 \mathrm{mV})$ on the electrocardiogram on exercise stress tests, or primary lung disease judged by history, clinical examination, chest $x$ ray film, and pulmonary function tests. Table 1 shows patient characteristics. Six of the patients had ischaemic heart disease and two had idiopathic dilated cardiomyopathy as the cause of their chronic heart failure. All patients were classified as New York Heart Association (NYHA) class II. Radionuclide gated ventriculography was performed before the study and the mean left ventricular ejection fraction was $30 \%(9 \%)$. The mean forced expiratory volume in one second was $2.5(0.4) 1$.

\section{STUDY PROTOCOI}

The study was approved by the ethics committee of the Royal Free Hospital and all patients gave written informed consent. 
Table 1 Patient characteristics

\begin{tabular}{|c|c|c|c|c|c|c|c|c|c|c|}
\hline Patient & $\begin{array}{l}\text { Age } \\
(y r)\end{array}$ & $\begin{array}{l}\text { Weight } \\
(\mathrm{kg})\end{array}$ & Aetiology & $\begin{array}{l}\text { Medication } \\
\text { (daily) }\end{array}$ & $\begin{array}{l}V o_{2} \max \\
\left(\operatorname{ml~min}^{-1} \mathrm{~kg}^{\prime}\right)\end{array}$ & $\begin{array}{l}L V E F \\
(\%)\end{array}$ & $C T R$ & $\begin{array}{l}F E V_{1} \\
\text { (\% predicted) }\end{array}$ & $\begin{array}{l}F V C \\
\text { (\% predicted) }\end{array}$ & $\begin{array}{l}F E V_{1} / F V C \\
(\%)\end{array}$ \\
\hline 1 & 52 & $75 \cdot 7$ & DCM & $\begin{array}{l}\text { Frus } 80 \mathrm{mg} \\
\text { Ena } 20 \mathrm{mg} \\
\text { Dig } 0.25 \mathrm{mg} \\
\text { Amio } 200 \mathrm{mg}\end{array}$ & $24 \cdot 63$ & 30 & 0.55 & $2.4(83)$ & $3.0(77)$ & 80 \\
\hline 2 & 64 & $93 \cdot 8$ & DCM & $\begin{array}{l}\text { Frus } 40 \mathrm{mg} \\
\text { Ena } 5 \mathrm{mg}\end{array}$ & $11 \cdot 70$ & 45 & 0.57 & $2.0(70)$ & $2 \cdot 8(74)$ & 71 \\
\hline 3 & 64 & $73 \cdot 7$ & IHD & $\begin{array}{l}\text { Frus } 80 \mathrm{mg} \\
\text { Cap } 50 \mathrm{mg} \\
\text { Dig } 0.25 \mathrm{mg} \\
\text { ISDN } 20 \mathrm{mg}\end{array}$ & 19.59 & 24 & 0.59 & $3 \cdot 1(100)$ & $4 \cdot 1(95)$ & 76 \\
\hline 4 & 66 & $97 \cdot 4$ & IHD & $\begin{array}{l}\text { Frus } 40 \mathrm{mg} \\
\text { Cap } 75 \mathrm{mg}\end{array}$ & $11 \cdot 13$ & 16 & 0.52 & $2 \cdot 4(83)$ & $3.5(84)$ & 70 \\
\hline 5 & 67 & $70 \cdot 0$ & IHD & $\begin{array}{l}\text { Frus } 40 \mathrm{mg} \\
\text { Dig } 0.25 \mathrm{mg} \\
\text { Amio } 200 \mathrm{mg}\end{array}$ & $17 \cdot 83$ & 40 & 0.53 & $3 \cdot 2(92)$ & $3.9(85)$ & 82 \\
\hline 6 & 69 & $75 \cdot 5$ & IHD & $\begin{array}{l}\text { Frus } 60 \mathrm{mg} \\
\text { Cap } 37.5 \mathrm{mg} \\
\text { ISDN } 30 \mathrm{mg}\end{array}$ & 14.69 & 23 & 0.61 & $2 \cdot 7(85)$ & $3.5(81)$ & 77 \\
\hline $\begin{array}{l}7 \\
8\end{array}$ & $\begin{array}{l}73 \\
73\end{array}$ & $\begin{array}{l}67 \cdot 0 \\
66 \cdot 7\end{array}$ & $\begin{array}{l}\text { IHD } \\
\text { IHD }\end{array}$ & $\begin{array}{l}\text { Dyazide } 1 \text { tablet } \\
\text { Frus } 80 \mathrm{mg} \\
\text { Lisin } 5 \mathrm{mg}\end{array}$ & $\begin{array}{l}12 \cdot 88 \\
15 \cdot 74\end{array}$ & $\begin{array}{l}31 \\
28\end{array}$ & $\begin{array}{l}0.48 \\
0.60\end{array}$ & $\begin{array}{l}2 \cdot 0(61) \\
2 \cdot 6(79)\end{array}$ & $\begin{array}{l}2.8(65) \\
3.6(84)\end{array}$ & $\begin{array}{l}71 \\
72\end{array}$ \\
\hline $\operatorname{Mean}(\mathrm{SD})$ & $66(7)$ & $77 \cdot 4(11 \cdot 8)$ & & & $16.02(4.54)$ & $30(9)$ & $0.56(0.04)$ & $2.5(0.4)$ & $3.4(0.5)$ & $75(5)$ \\
\hline
\end{tabular}

CTR, cardiothoracic ratio; DCM, dilated cardiomyopathy; $\mathrm{FEV}_{1}$, forced expiratory volume in one second, FVC, forced vital capacity; IHD, ischemic heart disease; LVEF, radionuclide left ventricular ejection fraction; $\mathrm{Vo}_{2} \max$, maximal oxygen consumption; Amio, amiodarone; Cap, captopril; Dig, digoxin; Dyazide, hydrochlorothiazid + triamterene; Ena, enalapril; Frus, frusemide; ISDN, isosorbide dinitrate; Lisin, lisinopril.

Exercise tests

Patients underwent exercise tests by bicycle ergometry with a mechanically braked bicycle ergometer (Monark-Crescent AB, Varberg, Sweden). An incremental protocol for the bicycle ergometer was used starting at $50 \mathrm{~W}$ of work, increasing the workload by $10 \mathrm{~W}$ $\min ^{-1}$ as tolerated, maintaining the flywheel rate at $50 \mathrm{rev} \mathrm{min}^{-1}$. Patients took their usual medications on the day of the exercise tests and all tests were performed in the morning at least two hours after eating. Heart rate, blood pressure, and respiratory rate were measured before exercise, every minute of exercise, at peak exercise, and until values returned to baseline.

Expired gases were analysed at rest until a steady state was achieved. Subjects wore a mouthpiece with a low resistance Hans Rudolf spiral non-return valve and the amount of dead space in the circuit was estimated as $35 \mathrm{ml}$. Minute ventilation (VE, in $\left.1 \mathrm{~min}^{-1}\right)$, oxygen consumption $\left(\mathrm{Vo}_{2}\right.$, in $\mathrm{ml}$ $\mathrm{min}^{-1} \mathrm{~kg}^{-1}$, and carbon dioxide production $\left(\mathrm{VCO}_{2}\right.$, in $\left.\mathrm{ml} \mathrm{min}{ }^{-1} \mathrm{~kg}^{-1}\right)$ were measured by the argon dilution method every 10 seconds from a mixing box by an AirSpec MGA200 mass spectrometer (Airspec, Bromley, Kent). ${ }^{8}$ This output was linked by an analogue to digital converter to an on line BBC micro computer. Values were corrected for atmospheric pressure, laboratory temperature, watervapour pressure, and body weight. Ventilatory variables were calculated over the 30 seconds before and after the end of each minute, and maximal ( $\max$ ) values derived from the last 60 seconds of exercise. Arterial oxygen saturation was measured with an earlobe pulse oximeter (Radiometer, Copenhagen, Denmark).

During exercise, the magnitude of the sensation of dyspnoea was assessed with a hand written $100 \mathrm{~mm}$ visual analogue scale (VAS), at the end of each three minute stage, at peak exercise, and at 15,30, and 60 seconds then each minute after exercise until values returned to baseline. ${ }^{9}$

\section{Ventilation and perfusion scanning}

Ventilation and perfusion scanning was performed at rest and on exercise on separate occasions within two weeks. Bicycle ergometry was repeated in the Department of Medical Physics according to the same protocol.

At bicycle ergometry, patients were positioned directly in front of a gamma camera (IGE 400T) so as to ensure optimal views in the posteroanterior plane. Heart rate and blood pressure were measured as before. Ventilation and perfusion scanning was performed at $80 \%$ of previous peak heart rate at ergometry. This point was chosen because it allowed sufficient time to perform both ventilation and perfusion scans before the end of exercise at peak capacity. Ventilation scanning was performed with krypton-81m $\left.{ }^{81 \mathrm{~m}} \mathrm{Kr}\right)$ by the continuous inhalation technique, ${ }^{10}$ with inhalation through a two way valve. A dose of $3000 \mathrm{MBq} \mathrm{s}$ of ${ }^{81 \mathrm{~m}} \mathrm{Kr}$ was delivered through a standard reservoir connected by tubing to the patient's mouthpiece over 100 seconds until 300000 counts were collected, with the window of the camera set for the $191 \mathrm{keV} \gamma$ rays of the ${ }^{81 \mathrm{~m}} \mathrm{Kr}$. Consecutively, an additional $100 \mathrm{~cm}$ length of tubing was connected to create added dead space (to ensure delivery at a later stage of inspiration) with further delivery of ${ }^{81 \mathrm{~m}} \mathrm{Kr}$ over 100 seconds. At the same time $(80 \%$ of the previous peak heart rate), $80 \mathrm{MBq}$ of technetium-99m $\left({ }^{99 \mathrm{~m}} \mathrm{Tc}\right)$ macroaggregated albumin was injected intravenously and counts collected with the window of the camera set for the $140 \mathrm{keV} \gamma$ rays of the ${ }^{99 m} \mathrm{Tc}$. Ventilation and perfusion scans were recorded on a Nuclear Diagnostics computer system (Nuclear Diagnostics, Gravesend, Kent) and analysed by means of vertical profile information transferred to a personal computer. The scans were performed by two observers (JEA, AGI) independent of the supervision of the exercise protocol (NGU, SLJ).

On another day, ventilation and perfusion 
Figure 1 Lung activity from krypton $-81 m$ inhalation and technetium$99 m$-macroaggregated albumin injection normalised to 100 across the right lung field from base to apex $(A)$ at test and $(B)$ up to peak exercise in patient 1. (C) The summed ventilation to perfusion difference from base to apex at rest and (D) up to peak exercise, in the same patient. (- perfusion, - - ventilation).
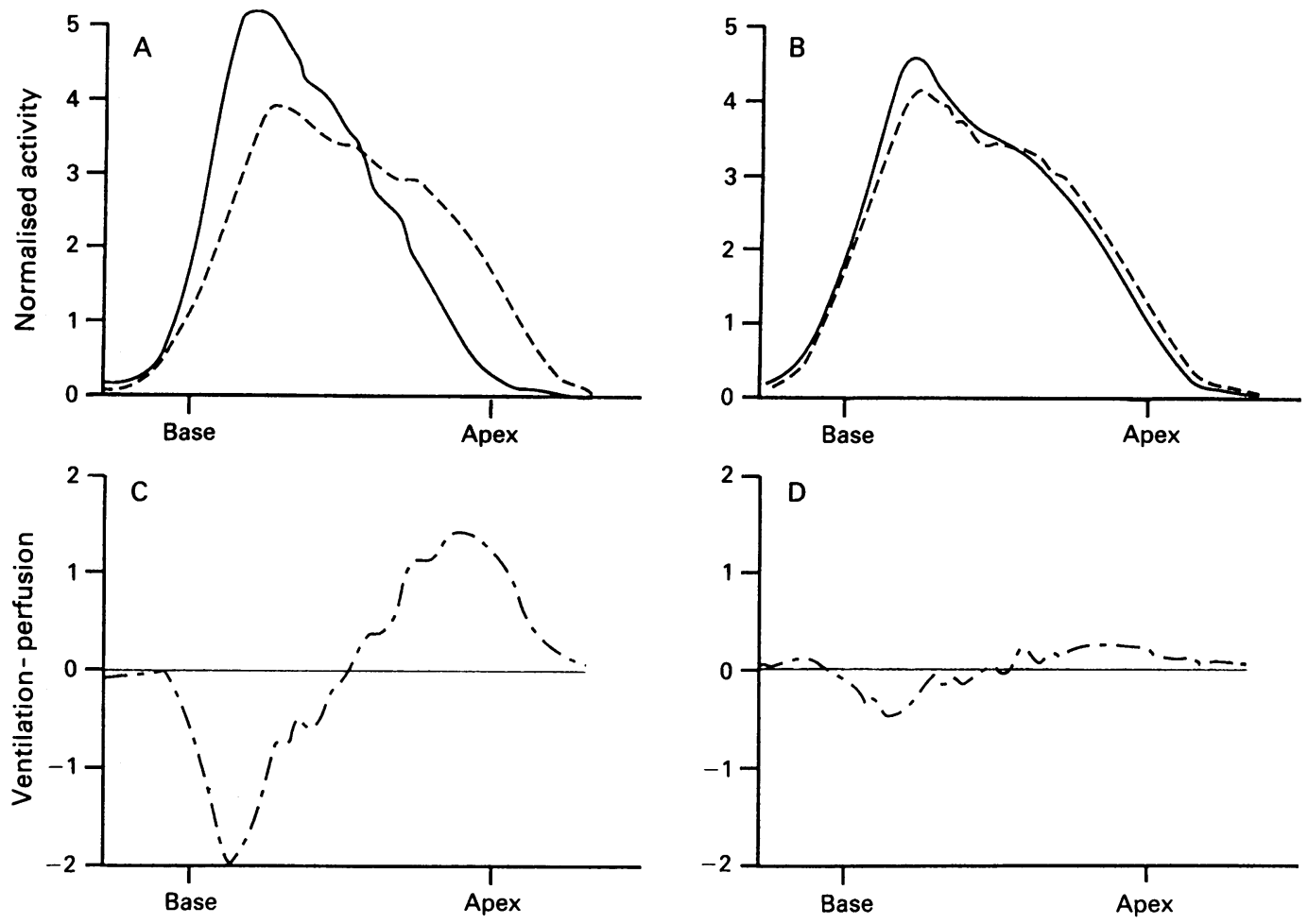

imaging was repeated with the patient seated at rest. Ventilation was scanned with delivery of ${ }^{81 \mathrm{~m}} \mathrm{Kr}$ from the standard reservoir and with and without added dead space. Images were taken in the posteroanterior plane as well as in right and left posterior oblique views.

\section{DATA ANALYSIS}

Vertical distributions of lung activity of ventilation and perfusion were assessed from right lung profiles (posteroanterior image). Activity was measured in a 16 pixel wide region of interest drawn down the centre of the lung profile and continuous curves of activity against lung position were plotted. Curve values were expressed as a percentage of total radioactivity delivered to the lung. All ventilation and perfusion scans were analysed by two observers (AGI, JEA) blinded to the exercise capacity or exercise duration of each individual patient.

An arbitrary index of $V / Q$ mismatch was calculated from the summation of the difference between ventilation and perfusion across the lung profile, and this mismatch index was expressed as units (fig 1). As well as the global $V / Q$ mismatch index at rest and at peak exercise, the difference between the two values was also calculated.

Estimation of anatomical dead space was calculated in individual patients with the for-

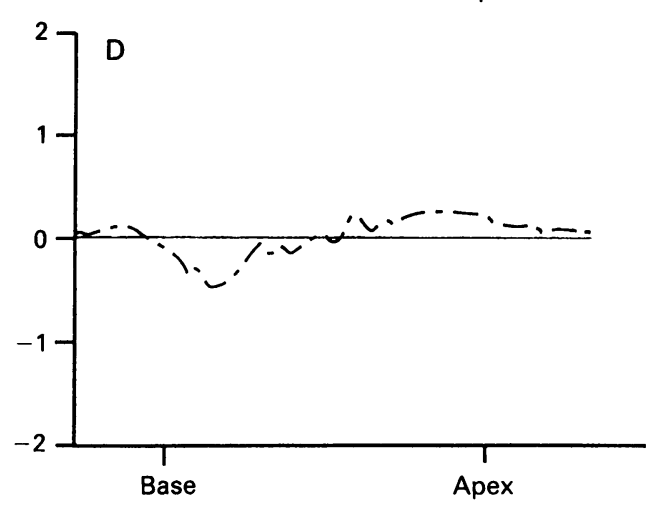

mula: anatomical dead space $=$ (body weight $\times 2 \cdot 2)+$ age, where weight is in kilograms and age in years. ${ }^{11}$ The total ventilatory response was calculated as minute ventilation divided by carbon dioxide production $\left(\mathrm{VE} / \mathrm{VCO}_{2}\right)$ over the duration of exercise. Alveolar ventilation was defined as: alveolar ventilation $\left(V_{A}\right)=V E-$ (respiratory rate $\times$ anatomical dead space).

\section{STATISTICAL ANALYSIS}

Values are expressed as mean (SD). Paired data were analysed by the Student's $t$ test. Stepwise regression analysis was used to find the model of the relation between measured values, and correlation coefficients were determined. A value of $p<0.05$ was considered significant.

\section{Results}

\section{EXERCISE TESTING}

Table 2 shows, the results at initial bicycle ergometry. The haemodynamic stress of exercise during ventilation and perfusion scanning was similar to that during expired gas analysis. Basal heart rate was 74 (7) beats min $^{-1}$ during scanning ( $v 76$ (6) beats $\mathrm{min}^{-1}$ previously), maximal heart rate was 128 (24) beats $\min ^{-1}$ ( $v 128$ (18) beats min $^{-1}$ previously), and exercise duration was 511 (115) s (v 553 (76) $\mathrm{s}$ previously). There was no significant change

Table 2 Bicycle ergometry

\begin{tabular}{|c|c|c|c|c|c|c|c|}
\hline $\begin{array}{l}\text { Heart rate } \\
\text { (beats } \text { min }^{-1} \text { ) }\end{array}$ & $\begin{array}{l}\text { Systolic } \\
\text { blood } \\
\text { pressure } \\
(\mathrm{mm} \mathrm{Hg})\end{array}$ & $\begin{array}{l}\text { Rate-pressure } \\
\text { product } \\
\left(\mathrm{mm} \mathrm{Hg} \mathrm{min}^{-1}\right)\end{array}$ & $\begin{array}{l}\mathrm{VO}_{2} \\
\left(\mathrm{ml} \mathrm{min}^{-1} \mathrm{~kg}^{-1}\right)\end{array}$ & $\begin{array}{l}V E \\
\left(\min ^{-1}\right)\end{array}$ & $\begin{array}{l}\mathrm{VCO}_{2} \\
\left(\mathrm{ml} \min ^{-1} \mathrm{~kg}^{-1}\right)\end{array}$ & $V E / V \mathrm{CO}_{2}$ & $\begin{array}{l}\text { Duration } \\
(s)\end{array}$ \\
\hline $\begin{array}{l}\text { Rest } 76(6) \\
\text { Peak Exercise128 (16) }\end{array}$ & $\begin{array}{l}141(8) \\
183(15)\end{array}$ & $\begin{array}{l}10820(1330) \\
23420(3420)\end{array}$ & $\begin{array}{r}4.91(1.41) \\
16.02(4.54)\end{array}$ & $\begin{array}{l}11 \cdot 14(3 \cdot 67) \\
41 \cdot 7(10 \cdot 25)\end{array}$ & $\begin{array}{r}3.88(1.05) \\
16.64(5.01)\end{array}$ & $\overline{2.58}(0.48)$ & $\overline{511}(115)$ \\
\hline
\end{tabular}

Results are means (SD); VE, minute ventilation; $\mathrm{Vo}_{2}$, oxygen consumption; $\mathrm{VCO}_{2}$, carbon dioxide production. 

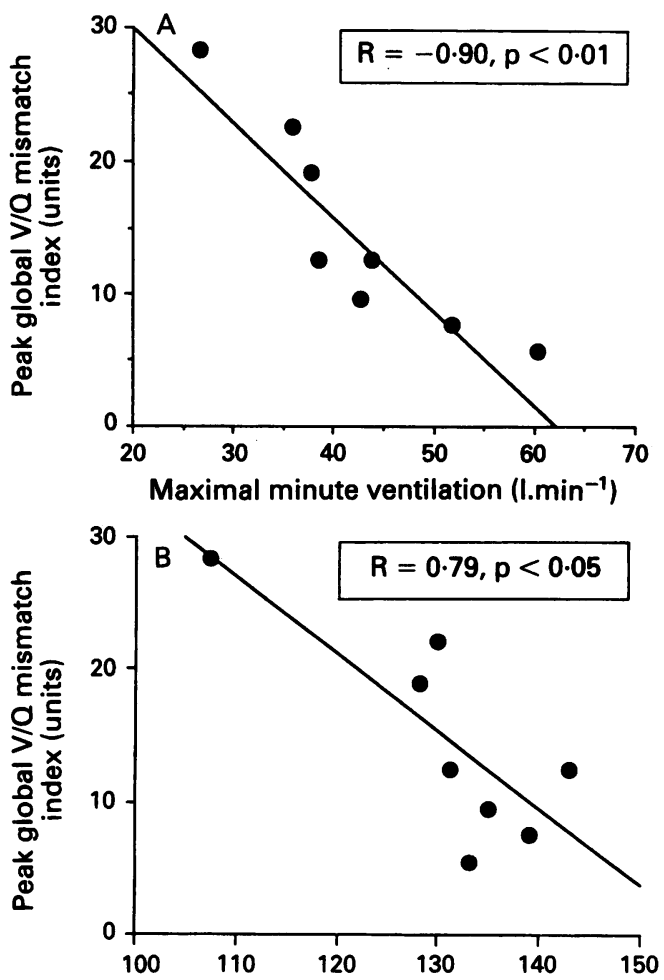

Maximal mean arterial pressure $(\mathrm{mm} \mathrm{Hg})$

Figure 2 Relation of maximal global VIQ mismatch index with $(A)$ maximal minute ventilation, and $(B)$ maximal mean arterial pressure.

in arterial oxygen saturation measured by ear lobe oximetry $(94 \%(3 \%)$ at rest and $95 \%$ (3\%) at peak exercise) at initial bicycle ergometry.

VENTILATION AND PERFUSION SCANNING Ventilation and perfusion scanning on exercise started at $80 \%$ of the previous maximal heart rate and thus at different work loads and levels of oxygen consumption. No relations were seen between global V/Q mismatch index at rest and left ventricular ejection fraction, resting mean arterial pressure, or systolic blood pressure, $\mathrm{VEmax}, \mathrm{VE} / \mathrm{VCO}_{2}$ or $\mathrm{VO}_{2} \mathrm{max}$.

At peak exercise, with stepwise regression, maximal global V/Q mismatch index was described by the function: 44.04 -0.7 VEmax, giving an $F$ ratio of $27.56(p<0.01)$. Maximal global V/Q mismatch index correlated negatively with VEmax $(R=-0.90$, $\mathrm{p}<0.01$ ) (fig 2), which was identical to maximal alveolar ventilation. A correlation was also found between maximal global V/Q mismatch index and maximal mean arterial pressure $(R=-0.79, p<0.05)$ (fig 2). No relation was found between global V/Q mismatch at peak exercise and exercise duration, $\mathrm{VE} / \mathrm{VCO}_{2}$ or $\mathrm{VO}_{2} \max$.

The difference in global $V / Q$ mismatch index at rest and at peak exercise was calculated. In one case (patient 2), there was an increase in global mismatch on exercise giving a negative value for reduction in global V/Q mismatch index. Nonetheless, global $\mathrm{V} / \mathrm{Q}$ mismatch index was reduced from 24.0
(5.9) units at rest to $14.9(7.9)$ units at peak exercise $(p<0.01)$ (fig 3$)$. With stepwise regression, the reduction in global $V / Q$ mismatch index was described by the function:

$$
\begin{array}{r}
-80.99+0.95 . \mathrm{VO}_{2} \max +0.28 . \\
\text { VEmax }+0.43 \text {. MAPmax }
\end{array}
$$

(where MAPmax = maximal mean arterial pressure), giving an F ratio of 200.42 $(p<0.001)$. There was a significant relation between the reduction in global V/Q mismatch index and $\mathrm{Vo}_{2} \max (\mathrm{R}=0.88$, $\mathrm{p}<0.01$ ) (fig 4). A relation was also found between the reduction in global V/Q mismatch index and VEmax $(R=0.87$, $\mathrm{p}<0.01$ ) (fig 4). No correlations were found, however, between the reduction in global V/Q mismatch index and maximal mean arterial pressure, exercise duration, or $\mathrm{VE} / \mathrm{VCO}_{2}$.

There was no significant overall change in arterial oxygen saturation measured by ear lobe oximetry $(93 \%(2 \%)$ at rest and $93 \%$ (4\%) at peak exercise (fig 5), and no correlation was shown between arterial oxygen saturation and global $V / Q$ at rest or at peak exercise or with the change in oxygen saturation from rest and global V/Q reduction. Also, no relation was seen between either maximal global V/Q mismatch index or its reduction and the perception of dyspnoea measured by the visual analogue score during submaximal or peak exercise.
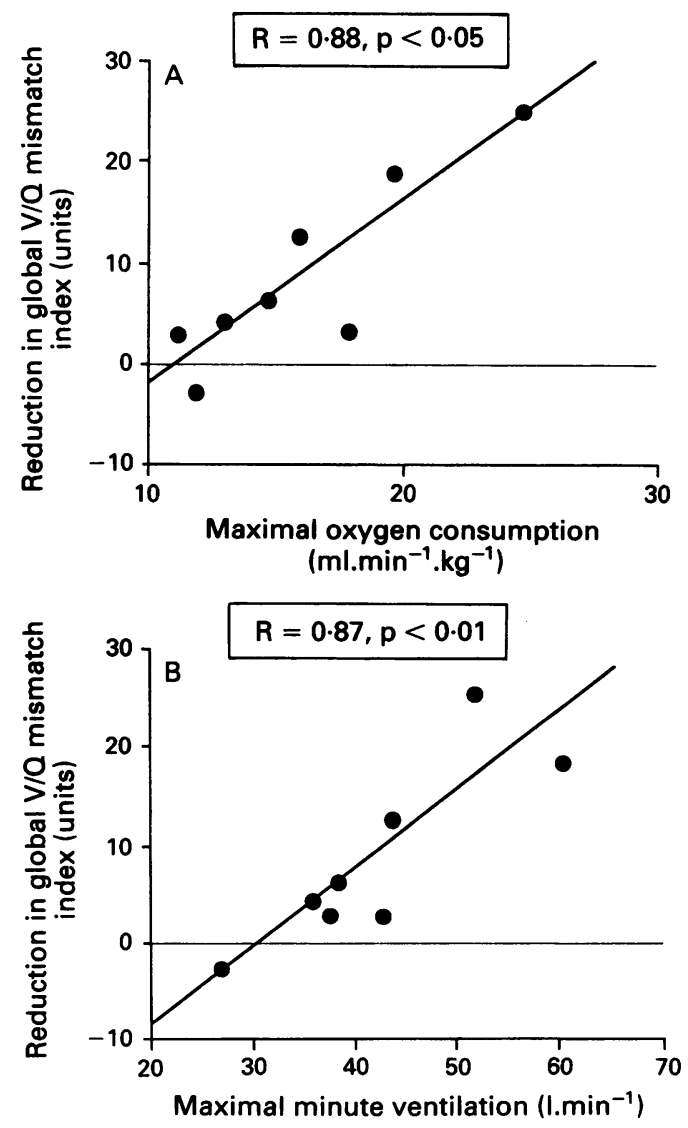

Figure 4 Relation of the reduction in global V/Q mismatch index with $(A)$ maximal oxygen consumption, and $(B)$ maximal minute ventilation. at peak exercise. 


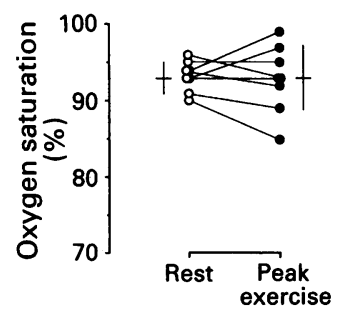

Figure 5 Individual data points of arterial oxygen saturation at rest and at peak exercise.

\section{Discussion}

Previous work has suggested that the increased ventilation of exercise in chronic heart failure may occur as a response to an increase in physiological dead space. ${ }^{2-6}$ In these patients there is a linear inverse relation between minute ventilation over carbon dioxide production $\left(\mathrm{VE} / \mathrm{VCO}_{2}\right)$ and maximal oxygen consumption. ${ }^{12}$ As correction for ventilation of anatomical dead space only reduces the gradient of the inverse relation by one third, it has been suggested that increased physiological dead space, that is an increased V/Q mismatch, accounts for most hyperpnoea, and that this mismatch correlates directly with maximal oxygen consumption. ${ }^{6}$

By contrast, Davies and coworkers showed that there was no such correlation between $\mathrm{VE} / \mathrm{VCO}_{2}$ and maximal oxygen consumption in normal healthy subjects ${ }^{5}$ and there seemed to be a curvilinear relation between $\mathrm{VE} / \mathrm{VCO}_{2}$ and maximal oxygen consumption, when combining this with data from patients with chronic heart failure. It was suggested that the point of inflection of this curve represented a threshold of severity of chronic heart failure beyond which $\mathrm{VE} / \mathrm{VCO}_{2}$ increased due to $\mathrm{V} / \mathrm{Q}$ mismatch, and that this might be due to insufficient cardiac function to perfuse all lung zones. ${ }^{5}$

The results of this study indicate that it is possible to show V/Q mismatch in chronic heart failure patients at rest with a simple method of quantitation. As with many other resting measurements of cardiorespiratory function in chronic heart failure patients ${ }^{1314}$ V/Q mismatch at rest does not correlate with subsequent exercise capacity. The degree of global mismatch at peak exercise, however, is inversely related to maximal minute ventilation. On exercise, there is a tendency to reduce this mismatch, and this correlates well with exercise capacity measured by maximal oxygen consumption, as well as with maximal minute ventilation. The increase in mean arterial pressure at peak exercise, which may be a measure of the ability adequately to perfuse all regions of the pulmonary vascular bed, also correlated with the reduction in global V/Q mismatch. Thus although we cannot prove a causal relation it is possible that the ability to increase cardiac output to perfuse the lungs adequately and match the increase in alveolar ventilation on exercise is what partly determines the delivery of oxygen to exercising muscles.

Gravity is a considerable influence on regional ventilation and perfusion in the normal lungs, with a gradient in flow from the apex to the base, ${ }^{15-17}$ with reduced arterial pressure at the apices, as well as a central to peripheral reduction in pulmonary blood flow. Regional perfusion is also dependent on the arteriolar resistance and hypoxic vasoconstriction. ${ }^{18}$ On exercise, there is a considerable increase in recruitment of additional vascular channels in the pulmonary circulation and widespread pulmonary vasodilatation to accommodate the increase in pulmonary blood flow. Chronic heart failure results in redistribution of pulmonary blood flow away from dependent areas at rest to the apices, ${ }^{19}$ with an inability to increase the proportion of upper zone perfusion on exercise by contrast with controls. ${ }^{20}$ This lack of change in perfusion to the upper zones may reflect the inability to reduce mismatch on exercise in patients with more severe heart failure. Furthermore, as this is only partially relieved by increasing lung volume, ${ }^{21}$ or oxygen, ${ }^{22}$ it may be that there are structural or functional alterations in these areas that compound a reduced regional lung perfusion on exercise through an inadequate cardiac output.

\section{LIMITATIONS OF THE STUDY}

A potential limitation of this study is that ventilation and perfusion scanning was performed separately from expired gas measurement. This obviated the use of an arbitrary level of oxygen consumption as the starting point for scanning during sub-maximal exercise. Both the heart rate response to exercise and exercise duration were not significantly different from that during expired gas analysis, implying similar exercise haemodynamics. As scanning was initiated at this point, patients were also performing different workloads that could contribute to different degrees of cardiovascular work. Although it is possible that patients with worse heart failure were able to exercise for less time and could not reduce $V / Q$ mismatch for this reason, this still does not exclude the inability to reduce mismatch as a possible limiting factor in exercise.

\section{CONCLUSIONS}

It is possible to measure $V / Q$ mismatch in patients with chronic heart failure at rest and on exercise with vertical lung profiles of ${ }^{81 \mathrm{~m}} \mathrm{Kr}$ gas inhalation and intravenous ${ }^{99 \mathrm{~m}} \mathrm{Tc}$. On exercise, global V/Q mismatch tends to diminish. The ability to reduce this mismatch correlates well with maximal exercise capacity as assessed by maximal oxygen consumption and with maximal minute ventilation, and to a lesser extent with maximal mean arterial pressure. This implies that the inability to perfuse all regions of lung adequately on exercise through a reduced cardiac output is one of the factors determining exercise capacity in chronic heart failure.

We thank Ian Watson at the MRC Cyclotron Unit, Hammersmith Hospital, London for providing hot generators for this study.

1 Weber KT, Kinasewicz GT, Janicki JS, Fishman AP Oxygen utilisation and ventilation during exercise in patients with chronic stable congestive heart failure. Circulation 1982;65:1213-23.

2 Wilson JR, Ferraro N. Exercise intolerance in patients with chronic left heart failure: relation to oxygen transport and ventilatory abnormalities. Am $g$ Cardiol port and ventilato

3 Rubin SA, Brown HV. Ventilation and gas exchange during exercise in severe chronic heart failure. $A m R e v$ ing exercise in severe ch

4 Sullivan MJ, Higginbotham MB, Cobb FR. Increased exercise ventilation in patients with chronic heart failure: intact ventilatory control despite haemodynamic ure: intact ventilatory control despite haemodynamic

5 Davies SW, Emery TM, Watling ML, Wannamethee G, Lipkin DP. A critical threshold of exercise capacity in 
the ventilatory response to exercise in chronic heart failure. Br Heart f 1990;65:179-83.

6 Buller NP, Poole-Wilson PA. Mechanism of the increased ventilatory response to exercise in patients with chronic heart failure. Br Heart ₹ 1990;63:281-3.

7 Sullivan MJ, Knight ID, Higginbotham MB, Cobb FR. Relation between central and peripheral hemodynamics during exercise in patients with chronic heart failure. during exercise in patients

8 Davies N, Denison DM. Measurement of metabolic gas exchange and minute ventilation by mass spectrometry alone. Respir Physiol 1979;36:261-7.

9 Davies SW, Jordan SL, Lipkin DP. Statistical considerations in the measurement of dyspnoea [abstract]. Clin Sci 1990;79 (suppl 23):5P.

10 Fazio $F$, Jones $T$. Assessment of regional ventilation by continuous inhalation of radioactive Krypton-81m. Br Med f 1975;265:673-6.

11 Cotes JE, ed. Lung function: assessment and application in medicine. 4th ed. Oxford: Blackwell Scientific Publications, 1979;244-8.

12 Fink CI, Wilson JR, Ferraro N. Exercise ventilation and pulmonary artery wedge pressure in chronic congestive pulmonary artery wedge pressure in chronic

13 Higginbotham MB, Morris KG, Conn EH, Coleman RE, Cobb FR. Determinants of variable exercise performance among patients with severe left ventricular dysfunction. Am 7 Cardiol 1983;51:52-60.

14 Franciosa JA, Park M, Levine TB. Lack of correlation between exercise capacity and indexes of resting left ventricular performance in heart failure. $\mathrm{Am} \mathcal{F}$ Cardiol 1981;47:33-9.

15 Amis TC, Jones HA, Hughes JMB. Effect of posture on inter-regional distribution of pulmonary ventilation in man. Respir Physiol 1984;56:145-67.

16 Amis TC, Jones HA, Hughes JMB. Effect of posture on inter-regional distribution of pulmonary perfusion and VA/Q ratios in man. Respir Physiol 1984;56:169-82.

17 Harf A Pratt T, Hughes JMB Regional distribution of VAVQ in man at rest and with exercise measured with krypton-81m. F Appl Physiol 1978;44:115-23.

18 Hughes JMB. Distribution of pulmonary blood flow. In Crystal RG, West JB, eds. The lung: scientific foundations. New York: Raven Press 1991:1135-45.

19 Friedman WF, Braunwald E. Alterations in regiona pulmonary blood flow in mitral valve disease studied by radioisotope scanning. Circulation 1966;34:363-76.

20 Mohsenifar Z, Amin DK, Shah PK. Regional distribution of lung perfusion and ventilation in patients with chronic congestive heart failure and its relationship to cardiopulmonary hemodynamics. Am Heart $\mathcal{F}$ 1989; 117:887-91.

21 Hughes JMB, Glazier JB, Rosenzweig DY, West JB. Factors determining the distribution of pulmonary Factors determining the distribution of pulmonary blood flow in patients with raised

22 Dawson A, Kaneko K, McGregor M. Regional lung function in patients with mitral stenosis studied with xenontion in patients with mitral stenosis studied with xenon1965;44:999-1008. 